\title{
Moving mountains with mobiles: Spatio- temporal perspectives on mHealth in Nepal
}

\section{Arul Chib, Faiz B. Mohd Irwan Law, Muhammad Nazran Ahmad \& Nadia Bte Mohamed Ismail}

MedieKultur 2012, 52, 100-114

Published by SMID | Society of Media researchers In Denmark | www.smid.dk The online version of this text can be found open access at www.mediekultur.dk

Community healthcare workers (CHW) are an important component of rural healthcare service delivery to remote rural communities in developing countries. The field of mHealth proposes that mobile technologies will have a beneficial impact on rural healthcare development. Current analyses advance the proposition that the utilization of mobile technologies leads to the shifting of space and time (Ling \& Campbell, 2009). The current research examined the potential for a sustainable mHealth system for CHW in Achham, Nepal. The community aspect of mobile usage was overlaid with a spatio-temporal lens to examine the information and communication needs and practices of stakeholders within the healthcare infrastructure. Fieldwork was conducted in conjunction with Nyaya Health, at the Bayalpata Hospital, in Accham, Nepal. Qualitative research methods, focus group discussions, and in-depth interviews included 57 respondents.

The findings revealed that limited relevance and information-sharing, limited access due to individual ownership and low income, and ineffective training programs were key barriers to the delivery of rural healthcare services. The spatio-temporal perspective, particularly community communicative practices, revealed technological $m$ Health design solutions to alleviate the problems identified. The potential shifts in power relationships by using mobile technologies and hybrid fixed-wireless technologies provide opportunities for further theoretical investigation. 


\section{Introduction}

Advances in the delivery of maternal healthcare over the past century have resulted in vital gains in life expectancies, lowering of child mortality rates, and improved access to critical medication and medical expertise (World Health Organization [WHO], 2008). However, the distribution of healthcare benefits continues to exhibit significant variation (You, Wardlaw, Salama, \& Jones, 2009), extending from the global north-south divide to a rural-urban divide. The phenomenon of inverse care, whereby those with the greatest resources appropriate the best healthcare to the detriment of those in real need, often those least able to access and afford it (WHO, 2008), is often driven by public health spending policies that bias resource allocation of healthcare (Brant, Garris, Okeke, \& Rosenfeld, 2006). As a consequence, urban births receive greater medical attention than rural births by a factor of two (United Nations Children Fund [UNICEF], 2008).

Critical to the process of primary healthcare service delivery to rural populations are community health workers (CHW) (WHO, 1978) - i.e., non-professional health providers without extensive formal training, chosen by, and accountable to, their own local community (WHO, 2007). Normally compensated minimally with an honorarium (Bhattacharyya, Winch, LeBan, \& Tien, 2001), CHW provide a range of services (Bhutta, Darmstadt, Hasan, \& Haws, 2005; Bryce et al., 2005), helping to keep diseases at bay (Kahssay, Taylor, \& Berman, 1998; Witmer, Seifer, Finocchio, Leslie, \& O’Neil, 1995), eventually leading to a positive impact on maternal and infant healthcare (Lewin et al., 2006; Quinn et al., 2005; Sazawal \& Black, 2003).

However, rural CHW suffer from illiteracy and a lack of appropriate medical knowledge (Chen et al., 2004), often combined with inadequate training (Kruske \& Barclay 2004; McNamara, 2003; O'Heir, 1997). Coupled with a difficult to access and hierarchical medical infrastructure lacking a mechanism for two-way communication, $\mathrm{CHW}$ often lack operational effectiveness (Haines et al., 2007).

Mobile phones (MP) have bridged these healthcare service delivery gaps by delivering information, improving knowledge levels, and providing critical communication links (Chib, 2010; Kanter, Mechael, Lesh, Dhadialla, \& Kramers, 2008; Olla \& Tan; 2008). In particular, mobile phones have provided instantaneous voice and information transfer to semi-literate CHW and patients (Grameen Foundation, 2011; Zerroug \& Sari, 2009). Further, the vast majority (73\%) of the 5.3 billion global mobile phone users are located in developing countries, with penetration increasingly reaching remote rural areas (International Telecommunications Union [ITU], 2010). MP have been used to access accurate medical information in a timely manner (Angelidis, 2008), provide pre-treatment of primary healthcare problems (Bali \& Singh, 2007), improve internal communication within the complex healthcare system (Malkary, 2006) and with the external patient community (Harper, 2006), integrate data in the form of electronic medical records for efficient tracking (Anantraman et al., 2002; Chetley, 2006), and improve administrative efficiency of healthcare providers (Baker, 2006). 
A review of the mHealth, or mobile phones in healthcare, field in the context of developing countries (Mechael et al., 2010) suggests a growing body of evidence, particularly in peer-reviewed journals, that points to increasing rigor in the field. Yet, much of the literature reviewed focuses on implementations and their evaluations; there is a gap in the communicative practices surrounding mHealth technologies. To fill this, we examine the potential of developing a mHealth system for deployment with rural $\mathrm{CHW}$ in a remote mountainous region of Nepal.

\section{Theoretical approach}

Ling and Campbell (2009) extend the spatio-temporal arguments of Castells (1989, 2007), focusing on mobile communication practices, covering issues of coordination, mobility, and co-presence, across a variety of situations. Most relevant here is the contribution of Steenson and Donner (2009), which highlights device-sharing aspects of MP by multiple individuals in developing countries, driven by economic constraints and the presence of community networks.

Such mobile phone sharing practices_are relevant to rural mHealth projects in developing countries. Various stakeholders within the healthcare infrastructure are scattered across multiple locations, with little resources devoted to village-based $\mathrm{CHW}$ working at the margins of the system. The use of mobile communication technologies allows these diffused networks to derive benefits from micro-coordination, to conduct business in patients' homes, in mobile clinics, and hospitals, and to negotiate multiple relationships (Baker, 2006; Chib, 2010; Harper, 2006; Malkary, 2006).

Nevertheless, current theorizing about the space-and-time shifting characteristics of mobiles is limited to mobile practices post-adoption, viz., actual usage. This study aims to further the application of the spatio-temporal perspective of mobile communication by applying it to a context in which mobile phone usage is still a rarity. The mHealth context examined here takes the form of designing a mobile platform for hitherto non-users of mobile phones. The study focuses on the community practices that exhibit the richest and most relevant spatio-temporal characteristics, as this offers both an opportunity for extension, applied to a health context, and a point of departure, suggesting that non-users may exhibit certain practices that would be useful to designers of mobile phone projects.

Given this context, the study is situated within the Technology-Community-Management Vulnerabilities (TCMV) framework (Chib \& Ale, 2009). The model proposes that sustainable information and communication technology (ICT) implementations hinge upon three key intersections of technology, community, and management, while being subject to a range of vulnerabilities.

The TCMV model proposes that technological design is a combination of software and hardware components, while project management requires financial expertise, collaborative partnerships, and a supportive regulatory environment. Essential to success is relevance 
to community needs, community involvement via ownership and access, and participation in training programs. The four dimensions of vulnerabilities identified include physiological/psychological, informational, economic, and socio-cultural vulnerabilities. Finally, financial and social sustainability are dependent on the replicability and scalability of projects.

A review of the use of technology in the healthcare literature suggests that the TCMV model can be applied in general to eHealth, and specifically to the mHealth context. First, technological advancements in the medical field have been discussed in studies focusing on tele-medicine (Geissbuhler, Bagayokoa, \& Ly, 2007; Hsieh, Hjelm, Lee, \& Aldis, 2001), health information systems (HIS) (Germanakos, Mourlas, \& Samaras, 2006; Pagliari, Sloan, \& Gregor, 2005), and electronic medical records (EMR) (Dick \& Steen, 1991; Grimson, 2001; Zheng, Chib, Gao, \& Wang, 2011). However, given the developing country context of this study, rather than debating the merits afforded by various technological options, the article focuses on the context of mHealth because of the potential this technology affords versus others such as the Internet. The vast majority (73\%) of the 5.3 billion global mobile users (versus 1.2 billion Internet users) are located in developing countries, with penetration (68\% versus $21 \%$ online) increasingly reaching remote rural areas (International Telecommunications Union [ITU], 2010).

To understand the impact of rapidly diffusing mobile technology, we concentrate on the factors of relevance to the local community within the TCMV model. This component deals with the involvement and participation of the community, defined here as stakeholders within the healthcare system (Parmar, Keyson, \& deBont, 2007; Weigel \& Waldburger, 2004). The basic information needs of the community are a vital factor, yet are often ignored at the lower levels of the healthcare hierarchy (Pakenham-Walsh, 2000). Certainly, modes of ownership of, and access to, the technology are critical first steps in technology introduction programs (Byrne \& Sahay, 2006). Beyond access, there is a dire need for training in the use and management of the technology (Lee \& Chib, 2008).

The vulnerabilities dimensions affect both the adoption of technology and its potential impact on ultimate health indicators. The physiological-psychological dimension is a microlevel vulnerability concerning the mental and physical well-being of individuals and the community. The inadequate living conditions of the rural poor affect their general outlook on life (Roman, 2004) and subsequent adoption of technology. Socio-cultural vulnerabilities suggest a lack of equal opportunities for all members of a community, driven by the social structure and values of society that define the human relationships contained therein. These hierarchies of gender, race, religion, caste, and class affect access to resources and the decision making powers afforded by technology (Mitter, 2005; Whitten, Sypher, \& Patterson, 2000).

CHW feel reluctant to accept any technological intervention because of a lack of confidence in their ability to use technology (Christoph, Schoenfeld Jr., \& Tansky, 1998; Ramachandran \& Canny, 2008; Schaper \& Pervan, 2007). Poverty, low income, and lack of livelihood opportunities act as demand constraints, while developing country conditions of inadequate telecommunication and ancillary infrastructure act as supply constraints. Such eco- 
nomic vulnerability obstructs the adoption, implementation, and effective utilization of ICT, such as mobile phones (Chib et al., 2008).

Situated within the TCMV model, this study aims to answer the following research question: How does a spatio-temporal perspective shed light on the key community factors to take into consideration when designing mHealth implementations in resource-constrained environments?

\section{Context}

Nepal is a nation in need of improved healthcare; it is limited by slow economic growth, an unstable governance structure, and challenging geographical conditions. With average income below USD 0.50 a day, most villagers lack the financial means to access basic health services (Newar, 2007; Watchlist on Children and Armed Conflict, 2005). Consequently, maternal and infant mortality rates remain high in Achham district, the fieldwork site, relative to other regions in Nepal (America Nepal Medical Foundation, 2009; Bhattarai, 2010). Almost as alarming is the district's HIV incidence rate, i.e., Asia's highest (Kong, 2009). Other prevalent health issues are child malnutrition and diarrheal diseases.

To alleviate these health issues, a non-profit organization, Nyaya Health', runs a free healthcare centre, the Bayalpata Hospital, and a CHW program. The latter is organized to provide training and monthly compensation to $\mathrm{CHW}$, alongside the nationwide government-run Female Community Health Volunteers program.

\section{Methodology}

Fifty-one respondents were selected through snowball sampling from seven village development committees around Bayalpata Hospital, the research base; namely Bhagyaswor, Chandika, Janalikot, Mangalsen, Mastamandu, Ridikot, and Siddhaswor. In December 2009, qualitative interviews and focus-group discussions were conducted with 22 community healthcare workers, 10 professional management representatives (MG), and 19 patients and villagers (VL). All interviews were recorded on video. Comments included in the article are summarized as examples; however, individual names are withheld for reasons of confidentiality.

The interview guides were based on respondents' information and communication needs and current usage (experience, frequency, and modality) of mobile phones, split into categories of business (health) and personal use. Throughout the fieldwork, specific ethical procedures were followed. Informed consent forms were administered, and respondents were compensated with NPR 150 (USD 2).

With the help of a local interpreter, the research team kept detailed field notes of interviewees' responses. Debriefings were held regularly to ensure compliance with the research protocol. Digital recordings of all sessions were transcribed by a local Nepali academic to 
ensure accuracy, and transcripts were then translated into English. Thematic coding, involving the interpretation and categorization of information with reference to the themes in the context of the TCMV model's community framework, was used for data analysis.

\section{Findings}

While the overall results are described within the three dimensions of the TCMV aspect of community, viz., ownership, training and needs, and vulnerabilities, the findings section is structured around the lens of space and time reconstruction, and emergent communicative practices that may have implications for mHealth implementations.

\section{Perspectives on time}

The critical nature of the healthcare profession demands that information be made available immediately, particularly in the case of serious life-threatening situations, as emphasized by CHW17: "A new-born baby was not breathing normally. What was required was to blow in the baby's mouth, but we did not know that at that time." CHW expressed a felt need for an immediate response communication system should they encounter difficult or unfamiliar situations, especially in emergencies. As CHW14 stated, "in case of an emergency, it is not possible to use textbooks, so the best option at that time would be a telephone." However, only a minority of respondents had fixed-line telephones due to economic barriers, the lack of an extensive network, and the stifling bureaucratic procedures required to install one. Even in less critical cases, the resource-constrained supply chain required adherence to the regimen, as pointed out by CHW5: "We also have patients who have run out of medicines... so in those cases we get in touch with them."

Hospital administrators expressed the need to keep in regular contact with CHW to obtain patient information. In contrast, $\mathrm{CHW}$ wanted to communicate for administrative purposes. This symbiotic need was strongly expressed to resolve scheduling conflicts and better coordinate schedules within the hospital. Failures in such routine tasks were common, as illustrated by MG6: "one time I had incorrectly scheduled a meeting on a Wednesday when I was leaving on Tuesday, and I wasn't able to pass on the message and so the CHW ended up having to walk and then go back. I felt really guilty."

Of greater priority to $\mathrm{CHW}$ was training as a means to upgrading skills, as one $\mathrm{CHW}$ suggested: "Training is very important as it is the main source of information... if we do not get the right information people cannot use their full potential, so it will just go to waste." However, due to the pressure to spend time with patients, as well as to travel long distances, the duration of training seminars was often reduced... According to CHW3:

To totally eradicate these problems, we need proper training, and if we had received training every two months on how to take care of a baby, then we could have done a lot better 
and been successful... if we do not get any updates and training on this, then it tends to just slip out of our grasp.

In the remote reaches of the Himalayan regions, time is a precious resource for $\mathrm{CHW}$, needing to be prioritized based on regular healthcare duties, emergencies, travel, and administrative duties. MP have the potential to save time by improving efficiency, expanding time by allowing multi-tasking, and by allowing tasks to be re-scheduled.

\section{Perspectives on space}

Since the primary responsibility of the CHW-is to aid the village community distant from the hospital, the remote and displaced nature of the work environment leads to gaps in information retrieval and delivery of services, as highlighted by CHW5: "At times, the health camp and doctors are situated very far away, so in such cases we want to be able to treat the patients ourselves."

The hospital management devised regular information sharing sessions, by bringing the diffused hospital network together at a single location for monthly gatherings of a "small and tightly knit unit" of CHW. To circumvent the lack of a communication link as an informational barrier between the far-flung levels of the healthcare chain, respondents used individuals to relay information. Patients could take advantage of the regular access to the doctors available to the CHW. As patient (VL1) said: "In cases of emergency, we call the doctor through other people", or use peer-to-peer links between CHW, as described by the same respondent:

There are [other] CHWs nearby, so we discuss with them... She [other CHW) asks her [patient's regular CHW] to come to the post around 10:00am, and we go accordingly. So it means that you go after you have the information regarding their availability.

On a daily basis, the sheer risk involved in negotiating mountainous terrain, such as crossing rivers and walking down steep slopes, acts as a barrier, as CHW17 said: "[F]or an hour I need to walk through the jungle and I need to walk for another hour to get to the village." This situation intensifies when dealing with late night visits for emergency cases. The lengthy distance from an important stakeholder such as the local government hospital impeded the CHW' access to information, both in terms of inconvenience of the time lost, as well as the perceived emotional distance, since strong relationships could not be developed between stakeholders. According to $\mathrm{CHW} 9$ :

There is no proper facility or infrastructure here for giving us information and updates. When we go for trainings at the district, they train us, but do so half-heartedly. They are not interested in it. If it is three day training, they finish it off in one day. 
Achham's $C D M A^{2}$ cellular network was the only viable, ready, and relatively low cost mode of connectivity available. However, in distant villages, CHW1 pointed out, "(we) do not have the network towers in our area so mobiles are quite useless." For those in the management team who had MP, the CDMA network coverage around the hospital facility was erratic. When available, the signal strength was usually weak. Users would have to walk to certain spots or wait and try for a long time to get a proper connection. MG6 recounted her experience at Bayalpata Hospital:

This [CDMA mobile phone] won't work anywhere within the complex, within the whole area, until you walk [to] the public tap, that's on top of that hill, which is slightly more exposed...So for the first month and a half I was here, that's how we ordered medication, standing on that tap.

The vast and inhospitable distances across the mountainous Himalayan region made surmounting the notion of space a major ordeal for CHW. MP have the potential to improve the efficiency of the entire healthcare system by shrinking distances between far-flung locations, allowing information to flow from the central hospital to remote villages, and indeed, shift the boundaries of space by enabling greater emotional bonds amongst people and improving professional relationships located at great physical distances.

\section{Communicative practices}

The specific circumstances of tight-knit communities in rural Nepal led to the striking communicative practice of sharing telephonic access, both for fixed and wireless lines. To most respondents, MP seemed to be luxuries and was therefore less prioritized over basic commodities such as food, health, and education. VL2 mentioned the following: "You have to spend 5-6 hundred [NPR; USD 8] a month for it [mobile phone]. Where would we get that money from? This is a huge amount, enough to raise a child." Those who owned mobile phones, did so for business purposes (such as shopkeepers), or had greater economic status due to institutional affiliations.

An interesting communicative practice was the communal use of CDMA fixed wireless phones as an alternative to fixed-line and mobile phones. These hybrid phones look like normal fixed-line phones, but connect to CDMA networks via a Re-Useable Identification Module (R-UIM) card. Small business owners simply topped up the prepaid card credits, and charged callers for individual units, with CHW1 reporting: "[I use it] from the market while at times I use my friend's cell phone." We should note that access to CDMA fixed wireless telephones was limited to villages with a certain minimum population level; isolated communities in hamlets would still need to walk considerable distances for access. In such cases, and in general, it was common for people to use their neighbour's telephone or relative's MP, as evidenced by CHW3: "If I get a cellular phone I will borrow it from the people in the community and my friends." Thus, people who did not have specific communication 
devices would seek those who did, to use MP, while the people who possessed them were accustomed to sharing them with the other people in the community.

A second communicative practice of interest was the preference for peer-sharing of medical information within healthcare worker networks. Health personnel higher up in the hierarchy, such as government health workers and doctors, preferred reading books or medical publications, but CHW did not, possibly a consequence of having had only minimal formal higher education. Thus, lower education levels acted as a psychological barrier to obtaining critical medical information. Instead, CHW preferred training seminars utilizing discussion formats, with video and practical demonstrations, as they found it easier to absorb the information via peer-sharing. This was echoed by MG4 in his statement:

We have meetings where we teach them about what we have learnt and have been trained on. We share that with the female health workers and then they go and share it with the others.

\section{Discussion}

Overall, the research indicates that the spatio-temporal perspective can potentially reveal technological design solutions for mHealth implementation. Information in a rural healthcare situation tends to be quite time-sensitive, with both immediacy benefits and long-term impact. Medical knowledge delivered via MP as a form of training could expand the time available to devote to medically-oriented tasks instead of wasting time travelling to centralized locations. However, critical information required during emergencies is currently unavailable, and would be a major benefit of a mHealth program.

Further, administrative efficiencies can be extracted from making location less of a hurdle for the day-to-day functioning of community healthcare workers. Scheduling meetings, managing patient queues and prescriptions, and eliminating distance, weather and terrain as obstacles to communication are obvious spatio-temporal (Ling \& Campbell, 2009) benefits of introducing mobile solutions in rural healthcare. With mobile phones, $\mathrm{CHW}$ can micro-coordinate (Ling \& Haddon, 2001), planning their patient and hospital visits better, transferring information across various diffused levels. Thus $\mathrm{CHW}$ can harness their relationships with peers such as other CHW, and develop new relationships between levels, such as with patients residing in villages and with doctors based in hospitals.

We find evidence of communicative sharing practices, described by Steenson and Donner (2009), in rural Nepal, as MP and CDMA fixed-wireless phones, informally and formally, are shared within the community. Shopkeepers and mobile-phone owners play the role of "hub individuals" and "sharing partners" (Ling \& Campbell, 2009, pp. 9-10).

The community sharing aspect has important implications for mHealth project implementations. First, it may be argued that providing mobile phones to $\mathrm{CHW}$ would still neglect the most critical level of stakeholder in the rural health service delivery system, 
viz., the village-based patient. The communicative sharing practices in existence suggest that this situation would be resolved by a negotiation process, whereby the CHW would become the proxy hub for the villages within her jurisdiction. Secondly, the high growth rates of mobile penetration in Asia, coupled with falling prices of handsets and airtime, suggest that it will not be long before most bottom-of-the-pyramid individuals can acquire handsets and pay for access.

We note, however, that the various vulnerabilities brought about by economic, physical/ psychological, informational, and socio-cultural issues, identified within the TCMV model, continued to act as structural issues, and would require a concerted management effort from various stakeholders to resolve. It is important to anticipate the fissures that mobile phone implementation for $\mathrm{CHW}$ would introduce into the existing social hierarchy. The material features (Ling \& Campbell, 2009) of the current hubs, namely the hospitals, imbue these locations and their management with a command-and-control sense of power. The dissolution of this centralized power via mobile phones to the far-flung posts of the CHW will bring with it a transformation of the hierarchical relationships from the hub to the edges of the spokes. CHW will be able to access information from the centre or from peers, to obtain training, and to micro-coordinate with patients and doctors - all without the necessity of administrative management. This would suggest that power embedded within relationships is an added dimension to space-and-time perspectives on MP usage; existing social hierarchies will come under pressure in unique ways with their introduction. Whether such social transformation would occur naturally or whether it would require negotiation to ease frictions, and how the transformation would occur, are questions that require further investigation.

From a theoretical perspective, further investigation is required into understanding the shifting definitions of mobility and the relation to space when confronted with particular communicative practices of developing countries. The CDMA fixed-wireless phone offers a hybridity that challenges much of the assumptions and theorizing concerning the mobile phone. Here is a fixed device that can be used while walking away from a location, thus allowing the type of "cocooning" described by Ito, Okabe, and Anderson (2009).

Simultaneously, the fixed-line physical nature of the machine allows both for conferring social status on the owner (obtaining a fixed-line telephone is a formidable task within the bureaucratic system), and acts as a deterrent to individual claims of ownership. Upon reflection, the technology may have arisen as a consequence of infrastructural issues, such as the prohibitive costs of installing fixed-line networks in remote mountainous regions, requiring a large antenna to catch the weak cellular signal, and electricity to power the hardware. Conversely, mobile phones that require a particular physical space, such as the water-tap on the hill, confer a location-specific rigidity and a public notion of what has been theorized as a mobile and private medium.

With mHealth attracting a greater number of adherents, investments in mobile technologies for rural health are likely to increase. Nonetheless, projects aiming at the introduc- 
tion of MP should investigate the social environments as well as the health infrastructures involved. The implications for the physical well-being of marginalized communities may very well be immense, but these opportunities need to be tempered with an understanding of the sociological impact that would need to be managed, aided by the latest developments in spatio-temporal theorizing regarding mobile phones.

\section{Notes}

1. The authors are grateful to Nyaya Health for providing access to their hospital and CHW program, as well as acting as a research partner.

2. Code Division Multiple Access refers to protocols used in $2 \mathrm{G}$ and $3 G$ wireless communication networks, and is a competing standard to GSM, which is more ubiquitous globally.

\section{References}

America Nepal Medical Foundation. (2009). ANMF Project 06NH001. Retrieved March 10, 2010 from: http://www.anmf.net/programs/projects/2006projects/06nh001.htm

Anantraman, V., Mikkelsen, T., Khilnani, R., Kumar, V.S., Machiraju, R., Pentland, A., et al. (2002). Handheld computers for rural healthcare: Experiences from research concept to global operations. Proceedings of Development by Design Conference, Bangalore, India, 1-10. Retrieved November 10, 2008 from: http:// kaash.sourceforge.net/doc/dyd02.pdf

Angelidis, P. (2008). Mobile telemonitoring insights. Medical informatics: Concepts, methodologies, tools, and applications, 1: 107-112. Retrieved November 15, 2008 from: http://www.vidavo.gr/files/encyclopedia_article_angelidis.pdf

Baker, B. (2006). Mobile phone text message based consultation: An investigation of current practice and associated best practice recommendations. Retrieved November 22, 2008 from: http://www.ehealthnurses. org.uk/pdf/mobreport.pdf

Bali, S., \& Singh, A.J. (2007). Mobile phone consultation for community health care in rural north India. Journal of Telemedicine and Telecare, 13(8): 421-424.

Bhattacharyya, K., Winch, P., LeBan, K., \& Tien, M. (2001). Community health worker incentives and disincentives: How they affect motivation, retention, and sustainability. Retrieved January 10, 2010 from: http:// pdf.dec.org/pdf_docs/PNACQ722.pdf

Bhattarai, A. (2010, January). Health is not the only disease. Hardnews. Retrieved January 10, 2010 from: http://www.hardnewsmedia.com/2010/01/3395

Bhutta, Z.A., Darmstadt, G.L., Hasan, B.S., \& Haws, R.A. (2005). Community-based interventions for improving perinatal and neonatal health outcomes in developing countries: A review of the evidence. Pediatrics: 115, 519-617.

Brant, S., Garris, M., Okeke, E., \& Rosenfeld, J. (2006). Access to Care in Rural China: a Policy Discussion. The Gerald R. Ford School of Public Policy, University of Michigan. Retrieved March 10, 2010 from: http://www.umich.edu/ ipolicy/china/1)\%20Access\%20to\%20Health\%20Care\%20in\%20Rural\%20 China,\%20A\%20Policy\%20Discussion.pdf

Bryce, J., Black, R.E., Walker, N., Bhutta, Z.A., Lawn, J.E., \& Steketee, R.W. (2005). Can the world afford to save the lives of 6 million children each year? The Lancet, 365: 2193-2200. 
Byrne, E., \& Sahay, S. (2006). Participatory design for social development: A South African case study on community-based health information systems. Information Technology for Development, 13(1): 71-94.

Castells, M. (1989). The informational city: Economic restructuring and urban development. Oxford: Blackwell.

Castells, M., Fernadez-Ardevol, M., Qui, J.L., \& Sey, A. (2007). Mobile communication and society: A global perspective. Cambridge, MA: MIT Press.

Chen, L., Evans, T., Anand, S., Boufford, J.I., Brown, H., Chowdhury, M., et al. (2004). Human resources for health: Overcoming the crisis. The Lancet, 364: 1984-1990.

Chetley, A. (ed.). (2006). Improving health, connecting people: The role of ICTs in healthcare sector of developing countries. infoDev Grant, 1254, 40. Retrieved February 25, 2010 from: http://www.healthlink.org.uk/PDFs/infodev_frame.pdf

Chib, A. (2010). The Aceh Besar midwives with mobile phones project: Design and evaluation perspectives using the information and communication technologies for healthcare development model. Journal of Computer-Mediated Communication, 15(3): 500-525.

Chib, A. \& Ale, K. (2009). Extending the Technology-Community-Management Model to Disaster Recovery in Asia. In Proceedings of IEEE international conference on Information and Communication Technologies and Development 2009.

Chib, A., Lwin, M., O, Ang, J., Lin, H. \& Santoso, F. (2008). Mobiles and midwives: Improving healthcare communications via mobile phones in Aceh Besar, Indonesia. Asian Journal of Communication, 18(4): 348-364.

Christoph, R.T., Schoenfeld Jr., G.A., \& Tansky, J.W. (1998). Overcoming barriers to training utilizing technology: The influence of self-efficacy factors on multimedia-based training receptiveness. Human Resource Development Quarterly, 9(1): 25-38.

Dick, R.S. and Steen, E.B. (1991). The Computer-Based Patient Record. National Academy Press, Washington, D.C., 1991.

Geissbuhler, A., Bagayoko, C.O., and Ly, O. (2007). The RAFT network: 5 years of distance continuing medical education and tele-consultations over the Internet in French-speaking Africa. International Journal of Medical Informatics, 76: 351-6.

Germanakos, P. Mourlas, C., and Samaras, G. (2006). A Mobile Agent Approach for Ubiquitous and Personalized eHealth Information Systems, IEEE Transactions on Computers: 1259-1273.

Grameen Foundation (2011). Mobile technology for community health in Ghana.

Grimson, J. (2001). Delivering the electronic healthcare record for the 21st century. International Journal of Medical Informatics, 64: 111-127.

Haines, A., Sanders, D., Lehmann, U., Rowe, A.K., Lawn, J.E., Jan, S., et al. (2007). Achieving child survival goals: Potential contribution of community health workers. The Lancet, 369(9579): 2121-2131.

Harper, A. (2006). The role of mobile phones in increasing accessibility and efficiency in healthcare. Retrieved November 22, 2008 from: http://www.remindpatients.com/alan_harper.pdf

Hsieh, R.K.C., Hjelm, N.M., Lee, J.C.K., \& Aldis, J.W. (2001). Telemedicine in China. International Journal of Medical Informatics, 61: 139-146.

International Telecommunications Union. (2010). ICT facts and figures. The world in 2010. Market information and statistics division. International Telecommunications Union.

Ito, M., Okabe, D., and Anderson, K. (2009). Portable objects in three global cities: The personalization of urban spaces. In R. Ling and S. Campbell (eds.). The Reconstruction of Space and Time through Mobile Communication Practices. Edison, NJ: Transaction Publishers.

Kahssay, H.M., Taylor, M.E., \& Berman, P.A. (1998). Community health workers: The way forward. Geneva: World Health Organization. 
Kanter, A.S., Mechael, P.N., Lesh, N., Dhadialla, P., \& Kramers, A. (2008, May 26). Open source mHealth applications and the Millennium Development Goals for Africa. Paper presented at the MIE 2008: eHealth beyond the horizon - Get IT there, Goteborg, Sweden. Retrieved November 22, 2008 from: http:// www.hst.aau.dk/ ska/MIE2008/Panels/MIE2008_UID445_BID292.pdf

Kong, Y.L. (2009, June 19). After surviving war, Achham battles Aids. Nepali Times, 456. Retrieved January 16, 2010 from: http://www.nepalitimes.com.np/issue/2009/

Kruske, S., \& Barclay, L. (2004). Effect of shifting policies on traditional birth attendant training. Journal of Midwifery of Women's Health, 49(4): 306-311.

Lee, S. \& Chib, A. (2008). Wireless initiatives for connecting rural areas: Developing a framework. In N. Carpentier \& B. De Cleen (eds.), Participation and media production. Critical reflections on content creation. ICA 2007 Conference Theme Book (pp. 113-128). Newcastle, UK: Cambridge Scholars Publishing.

Lewin, S.A., Babigumira, S.M., Bosch-Capblanch, X., Aja, G., van Wyk, B., Glenton, C., et al. (2006). Lay health workers in primary and community health care: A systematic review of trials. Retrieved March 9, 2010 from: http://www.who.int/rpc/meetings/

Ling, R., \& Haddon, L. (2001). Mobile telephony and the coordination of mobility in everyday life. Machines that become use. Rutgers University.

Ling, R., \& Campbell, S.W. (eds.). (2009). The reconstruction of space and time: Mobile communication practices. New Brunswick, London: Transaction Publishers.

Malkary, G. (2006). Healthcare without bounds: Trends in mobile communications. Retrieved October 12, 2008 from: http://www.spyglass-consulting.com/Abstracts/Spyglass_Mobile_Comm_abstract.pdf

McNamara, K.S. (2003). Information and communication technologies, poverty and development: Learning from experience. Proceedings from infoDev Annual Symposium. Geneva, Switzerland: The World Bank.

Mechael, P., Batavia, H., Kaonga, N., et al. (2010) Barriers and gaps affecting mhealth in low and middle income countries: Policy white paper. Draft. Centre for Global Health and Economic Development Earth Institute, Columbia University, New York.

Mitter, S. (2005). Globalization, ICTs, and economic empowerment: A feminist critique. In C. Ng, \& S. Mitter (eds.), Gender and the digital economy (pp. 29-54). New Delhi: Sage Publications.

Newar, N. (2007, October 19). Nepal's real heroines: Female community health volunteers bring medical care to the weak and sick in remote areas. Nepali Times, 371. Retrieved January 10, 2010 from: http:// www.nepalitimes.com/issue/371/Nation/14071

O'Heir, J.M. (1997). Midwifery education for safe motherhood. Midwifery, 13: 115-124.

Olla, P., \& Tan, J. (2008). Designing a mHealth framework for conceptualizing mobile health systems. In: J. Tan (ed.) Healthcare information systems and informatics: Research and practices. Idea Group Inc.

Pagliari, C., Sloan, D., Gregor, P. What is eHealth (4): A Scoping Exercise to Map the Field. Journal of Medical Internet Research, $7(1)$.

Pakenham-Walsh, N. (2000). Access to reliable information for healthcare workers in developing countries: an international perspective. Health Libraries Review, 17: 37-40.

Parmar, V., Keyson, D.V., \& deBont, C. (2007). Shaping social beliefs: A community sensitive health information system for rural India. International Federation for Information Processing, 241: 133-143.

Quinn, V.J., Guyon, A.B., Schubert, J.W., Stone-Jiménez, M., Hainsworth, M.D., \& Martin, L.H. (2005). Improving breastfeeding practices on a broad scale at the community level: Success stories from Africa and Latin America. Journal of Human Lactation, 21(3): 345-354.

Ramachandran, D., \& Canny, J. (2008). Applying persuasive technologies in developing regions. Proceedings from ACM Conference on Human Factors in Computing Systems: Workshop on Human-Computer 
Interaction for Community and International Development. Florence, Italy: Association for Computing Machinery Special Interest Group on Computer-Human Interaction.

Roman, R. (2004). Differential access to information and communication resources for rural development: A case study in India. Proceedings from International Communication Association Annual Meeting. NY: International Communication Association.

Sazawal, S., and Black, R.E. (2003). Effect of pneumonia case management on mortality in neonates, infants, and preschool children: A meta-analysis of community-based trials. The Lancet Infectious Diseases, 3: 547-556.Schaper, G.P., \& Pervan, L.K. (2007). ICT and OTs: A model of information and communication technology acceptance and utilisation by occupational therapists. International Journal of Medical Informatics, 76: 212-221.

Steenson, M., \& Donner, J. (2009). Beyond the personal and private: Modes of mobile phone sharing in urban India. In R. Ling and S. Campbell (eds.). The Reconstruction of Space and Time through Mobile Communication Practices (pp. 231-250). Edison, NJ: Transaction Publishers.

United Nations Children's Fund. (2008). Progress for children: A report card on maternal mortality. Retrieved March 9, 2010 from: http://www.uniceforg/publications

Watchlist on Children and Armed Conflict. (2005). Caught in the middle: Mounting violations against children in Nepal's Armed Conflict. Retrieved January 16, 2010 from: http://www.essex.ac.uk/armedcon/ story_id/000249.pdf

Weigel, G., \& Waldburger, D. (eds.) (2004). ICTAD - connecting people for a better world: Lessons, innovations and perspectives of information and communication technologies in development. Berne: SDC/GKP.

Whitten, P., Davenport, B., Sypher, H., and Patterson, J.D. (2000). Transcending the technology of telemedicine: an analysis of telemedicine in North Carolina. Health Communication, 12(2):109-135.

Witmer, A., Seifer, S.D., Finocchio, L., Leslie, J., \& O’Neil, E.H. (1995). Community health workers: Integral members of the health care work force. American Journal of Public Health, 85: 1055-1058.

World Health Organization. (1978). Declaration of Alma-Ata. Retrieved October 10, 2009 from: http:// www.who.int/hpr/NPH/docs/declaration_almaata.pdf

World Health Organization. (2007). Community health workers: What do we know about them? Retrieved March 9, 2010 from: http://www.who.int/hrh/documents/community

World Health Organization. (2008). The world health report - Primary healthcare: Now more than ever. Retrieved March 1, 2010 from: http://www.who.int/whr/2008/

You, D., Wardlaw, T., Salama, P., \& Jones, G. (2009). Levels and trends in under-5 mortality, 1998-2008. The Lancet, 375(9709): 100-103.

Zerroug, M., \& Sari, Z. (2009). Algeria: Innovative health care solutions enabled by technology development to meet critical needs in remote areas. In International Telecommunication Union (eds.) Question 14-2/2: Mobile eHealth solutions for developing countries. Geneva: ITU.

Zheng, W., Chib, A., Gao, P, \& Wang, K. (2011). Factors influencing physicians' intention to share electronic medical records: An empirical investigation in China. Media Asia, 38(1): 14-21. 
Arul Chib

PhD, Assistant Professor

Division of Public and Promotional Communication Wee Kim Wee School of Communication and Information

Nanyang Technological University, Singapore arulchib@ntu.edu.ss

Faiz B. Mohd Irwan Law Student

Division of Public and Promotional Communication School of Communication and Information Nanyang Technological University, Singapore faiz0001@ntu.edu.sg

Muhammad Nazran Ahmad Student

Division of Public and Promotional Communication School of Communication and Information Nanyang Technological University, Singapore nazran@ntu.edu.sg

Nadia Bte Mohamed Ismail Student Division of Public and Promotional Communication School of Communication and Information Nanyang Technological University, Singapore nadi0009@ntu.edu.sg 